\title{
Gene Expression in Placentas From Nondiabetic Women Giving Birth to Large for Gestational Age Infants
}

Reproductive Sciences

2015, Vol. 22(10) 1281-1288

(C) The Author(s) 2015

Reprints and permission:

sagepub.com/journalsPermissions.nav DOI: 10.1 I77/I9337|9|I5578928

rs.sagepub.com

(S)SAGE

\author{
F. Ahlsson, MD, PhD', H. Åkerud, MD, PhD', D. Schijven, MSc', \\ J. Olivier, $\mathrm{PhD}^{1,2,3}$, and I. Sundström-Poromaa, $M D$, PhD $^{1}$
}

\begin{abstract}
Gestational diabetes, obesity, and excessive weight gain are known independent risk factors for the birth of a large for gestational age (LGA) infant. However, only I of the 10 infants born LGA is born by mothers with diabetes or obesity. Thus, the aim of the present study was to compare placental gene expression between healthy, nondiabetic mothers $(n=22)$ giving birth to LGA infants and body mass index-matched mothers $(n=24)$ giving birth to appropriate for gestational age infants. In the whole gene expression analysis, only 29 genes were found to be differently expressed in LGA placentas. Top upregulated genes included insulin-like growth factor binding protein I, aminolevulinate $\delta$ synthase 2 , and prolactin, whereas top downregulated genes comprised leptin, gametocyte-specific factor I, and collagen type XVII $\alpha$ I. Two enriched gene networks were identified, namely, (I) lipid metabolism, small molecule biochemistry, and organismal development and (2) cellular development, cellular growth, proliferation, and tumor morphology.
\end{abstract}

\section{Keywords}

large for gestational age, placental gene expression, microarray, leptin, and prolactin

\section{Introduction}

The number of infants born large for gestational age (LGA) has increased during the last 2 decades. ${ }^{1}$ Besides being at increased risk of later development of obesity, type 2 diabetes, cardiovascular disease, prostate cancer, and breast cancer, women who themselves were born LGA are also at increased risk of giving birth to LGA infants. ${ }^{2}$

Maternal pregestational diabetes, gestational diabetes, obesity, and excessive weight gain are all established risk factors for LGA. ${ }^{3,4}$ The fetal hyperinsulinemic hypothesis ${ }^{5}$ stipulates that increased maternal insulin resistance leads to enhanced maternal hepatic glucose production, which in turn results in increased glucose shunting to the fetus, ultimately causing fetal hyperinsulinemia and enhanced fetal growth. ${ }^{6}$ However, only approximately 1 of the 10 infants born LGA is born by mothers with diabetes or obesity. ${ }^{2}$

Maternal overfeeding in rodents is associated with altered placental expression of several genes related to metabolic signaling, inflammation, fatty acid transporter proteins, and several growth regulatory imprinted genes. ${ }^{7,8}$ Further, protein restriction during pregnancy results in downregulation of genes involved in nucleotide metabolism and upregulation of genes associated with the $\mathrm{p} 53$ pathway, apoptosis, negative regulators of cell growth, negative regulators of cell metabolism, and genes related to epigenetic control. ${ }^{9}$ However, research on the human placenta has thus far mostly addressed hypotheses related to growth restriction, small for gestational age (SGA) infants, and preeclampsia, ${ }^{10,11}$ whereas studies of human placental gene expression in relation to excessive fetal growth are less frequent and mostly concerned with gestational diabetes. Among the few findings at hand, Diaz and colleagues suggested that the peroxisome proliferator-activated receptor $\gamma$ (contributing to placental development) expression in placenta is positively associated with birth size. ${ }^{12}$ Further, decreased messenger RNA and protein contents for insulin-like growth factor (IGF) I, IGF-II, and IGF-IR have been described in full-term placentas from LGA compared to appropriate for gestational age (AGA) and SGA newborns. ${ }^{13}$

In light of this, we hypothesized that genes in pathways involved in lipid and carbohydrate metabolism are differently

\footnotetext{
' Department of Women's and Children's Health, Uppsala University, Uppsala, Sweden

${ }^{2}$ Department of Behavioral Physiology, University of Groningen, Groningen, the Netherlands

${ }^{3}$ Centre for Gender Medicine, Karolinska Institutet, Stockholm, Sweden
}

Corresponding Author:

F. Ahlsson, Department of Women's and Children's Health, Uppsala University, SE-75I 85 Uppsala, Sweden.

Email: fredrik.ahlsson@kbh.uu.se 
expressed in placentas from nondiabetic mothers giving birth to LGA infants. Hence, the aim of the present study was to compare placental gene expression in nondiabetic healthy mothers giving birth to LGA infants with placental gene expression of body mass index (BMI)-matched mothers giving birth to AGA infants.

\section{Materials and Methods}

\section{Patients}

Placenta samples were collected from women delivering at the Department of Obstetrics, Uppsala University Hospital, as part of an ongoing longitudinal study on antenatal and postpartum depression (The BASIC study). Women were invited for participation in the BASIC study in gestational week 16 to 17 . The mothers received written information about the study objectives and written consent for collection of placental tissue was obtained. At present the Biology, Affect, Stress, Imaging and Cognition in Pregnancy and the Puerperium (BASIC) biobank contains fresh frozen placental tissue from 913 pregnancies. Demographic data, clinical variables, maternal health care, delivery, and neonatal outcomes were retrieved from the medical records. This substudy to the BASIC project was approved by the regional Ethics Committee of the Medical Faculty of Uppsala University.

Inclusion criteria for cases and controls in this substudy were mothers of caucasian origin, normal pregnancies, and normal deliveries. Exclusion criteria were continued smoking or alcohol use during pregnancy, any severe chronic disease (the only exceptions being euthyroid women on levothyroxine treatment), daily use of any prescribed medication (with the exception of levothyroxine), prepregnancy type 1 or type 2 diabetes, gestational diabetes, preeclampsia, gestational hypertension, gestational age $<35$ weeks, other severe obstetric complications, and maternal age $<18$ or $>42$ years. Based on these criteria, 22 mothers who had given birth to an infant that was LGA were ascertained. LGA was defined as birth weight above the 90th percentile. Twenty-four randomly selected controls, matched on age, parity, first trimester BMI, and gestational age at birth, who had given birth to an infant that was AGA, defined in this study as \pm 0.8 standard deviations (SDs) from the mean gestational weight, were included.

The exclusion of cases with gestational diabetes was ascertained by 5 random, nonfasting blood glucose measurements during pregnancy (gestational weeks 10-14, 25, 28-29, 33 and 37). If nonfasting blood glucose levels at any time exceeded 8.8 $\mathrm{mmol} / \mathrm{L}$, or glycosuria developed, or evidence of increased fetal growth was present (symphysis-fundal height deviation more than $5 \mathrm{~cm}$ from mean, fetal growth by ultrasound $>22 \%$, or polyhydramniosis), an oral glucose tolerance test (OGTT) was performed. In addition, all women with at least 2 risk factors for gestational diabetes (family history of type 2 diabetes, BMI $\geq 30.0 \mathrm{~kg} / \mathrm{m}^{2}$ at first antenatal booking, previous history of LGA infant, or born outside of Europe) were subjected to 2 OGTTs during the pregnancy, in gestational weeks 12 to 14 and 28 to 30 , respectively.
Placental tissue samples were obtained immediately following delivery. Two basal plate biopsy specimens of the maternal-fetal interface, approximately $2 \mathrm{~cm}$ in size, were excised from the central part of the placenta in a way that each sample contained the decidua basalis and villous placenta. Areas involving calcification or infarcts were avoided. The tissue samples were briefly washed in sterile phosphate-buffered saline and were immediately frozen and stored at $-70^{\circ} \mathrm{C}$.

\section{Microarray Expression Analysis}

Total RNA was prepared from frozen parts of the maternal side of the placenta. Total RNA was isolated using the miRNeasy mini kit (Qiagen, Hilden, Germany). Tissue was lysed with QIAzol reagent (Qiagen) using a rotor-stator homogenizer (up to $33.000 \mathrm{rpm}$; Ingenieursbüro CAT M Zipper Gmbh, type x120, Staufen, Germany), and chloroform (Sigma Aldrich, St Louis, Missouri) was added for phase separation. The rest of the procedure was performed as described in the manufacturer's protocol. RNA concentration was measured with ND-1000 spectrophotometer (NanoDrop Technologies, Wilmington, Delaware), and RNA integrity number (RIN) value $>6.0$ was confirmed by use of the Agilent 2100 Bioanalyzer system (Agilent Technologies Inc, Palo Alto, California). No difference in RNA concentrations between AGA and LGA placentas was found $(439 \pm 281$ vs $403 \pm 263 \mathrm{ng} / \mathrm{dl}, P=.6)$.

Total RNA of 250 nanograms of from each sample were used to generate amplified and biotinylated sense-strand complementary DNA (cDNA) from the entire expressed genome according to the Ambion WT Expression Kit (P/N 4425209 Rev C 09/2009) and Affymetrix GeneChip WT Terminal Labeling and Hybridization User Manual (P/N 702808 Rev. 5, Affymetrix Inc, Santa Clara, California). GeneChip ST Arrays (GeneChip Human Gene 1.0 ST Array) were hybridized for 16 hours in a $45^{\circ} \mathrm{C}$ incubator and rotated at $60 \mathrm{rpm}$. According to the GeneChip Expression Wash, Stain and Scan Manual (PN 702731 Rev 3, Affymetrix Inc) the arrays were then washed and stained using the Fluidics Station 450 (Affymetrix Inc) and finally scanned using the GeneChip Scanner $30007 \mathrm{G}$ (Affymetrix Inc).

\section{Microarray Data Analysis}

The raw data was normalized in the free software Expression Console provided by Affymetrix (http://www.affymetrix. com) using the robust multiarray average method first suggested by Li and Wong in 2001. ${ }^{14,15}$ Subsequent analyses of the gene expression data were carried out in the freely available statistical computing language $\mathrm{R}$ (http://www.r-project.org) using packages available from the Bioconductor project (www.bioconductor.org). In order to search for the differentially expressed genes between the LGA and the AGA groups, an empirical Bayes moderated $t$ test with robust regression was then applied, ${ }^{16}$ using the "limma" package. ${ }^{17}$ To address the problem with multiple testing, the $P$ values were adjusted using the method of Benjamini and Hochberg. ${ }^{18}$ For this exploratory 
study, a significance threshold $(P<.1)$ and a fold change of $>$ \pm 0.5 was used. The Genesis software, version 1.7.1 (http:// genome.tugraz.at/), was used to produce hierarchical clustering (average linkage and correlation similarity) and to visualize differentially expressed genes by heatmaps. ${ }^{19}$ The expression data were further analyzed using ingenuity pathway analysis (IPA) in order to determine significantly deregulated genes and pathways (Ingenuity Systems, Mountain View, California; www.ingenuity.com).

\section{Real-Time Quantitative Reverse Transcriptase Polymerase Chain Reaction Analysis}

The validity of the microarray results was tested via quantitative real-time polymerase chain reaction (qRT-PCR) employing the StepOne Plus qPCR machine (Applied Biosystems, Life Technologies, Carlsbad, California). At the time of validation, 2 additional LGA cases were available. For validation we selected 5 genes ( $L E P$, insulin-like growth factor binding protein $1[I G F B P-1], F O S B$, prolactin $(P R L)$, and $\alpha$-hemoglobin-stabilizing protein $[A H S P]$ ) which showed a fold change $>0.6$ in the microarray. Because commonly used housekeeping genes were differently expressed between cases and controls in the micro array, we chose HPRTl as reference gene for normalization. ${ }^{20}$ The cDNA synthesis was performed by the use of SuperScriptIII First strand Synthesis kit (Invitrogen, Carlsbad, CA) according to manufacturer's instructions. TaqMan Gene expression Assay primers, probes, and gene expression master mix (all Applied Biosystems, Life Technologies, Carlsbad, California) were used to run the qRT-PCR according to manufacturer's instructions. All samples were performed in triplicates and averaged for further calculations. Mean reaction efficiencies were calculated by LinReg. Gene expression values were calculated with the $\Delta \Delta \mathrm{Cq}$ method (ie, $\mathrm{RQ}=2^{-\Delta \Delta \mathrm{Cq}}$ ) to illustrate the differences between groups. $^{21}$

\section{Statistics}

Clinical characteristics of the pregnant women in the study were compared by means of independent $t$ tests or chisquare tests. Differences in gene expression between subsets were calculated using independent $t$ tests (validation study). Data were analyzed using the SPSS 20.0 software (SPSS Inc, Chicago, Illinois). Level of significance was set at $P<.05$. Data are presented as mean \pm standard deviation or median (range).

\section{Results}

\section{Study Population}

The characteristics of the mothers and the infants are presented in Table 1. Besides higher gestational weight gain among cases, no differences in clinical variables were found between cases and controls. Owing to high screening blood glucose values, 1 control was submitted to an OGTT, which was normal.
Table I. Demographic Variables in the LGA Cases and Healthy Controls. $^{\mathrm{a}}$

\begin{tabular}{lccl}
\hline & $\begin{array}{c}\text { Controls } \\
(\mathrm{n}=24)\end{array}$ & $\begin{array}{c}\text { Cases } \\
(\mathrm{n}=22)\end{array}$ & PValue \\
\hline Age, years & $31.7 \pm 4.2$ & $33.7 \pm 4.5$ & .2 \\
Parity, median (range) & $\mathrm{I}(0-2)$ & $\mathrm{I}(0-3)$ & .4 \\
Prepregnancy smokers, $\mathrm{n}(\%)$ & $\mathrm{I}(4.2)$ & $\mathrm{I}(4.5)$ & .6 \\
First trimester weight, kg & $72.9 \pm 9.0$ & $76.9 \pm 13.2$ & .3 \\
Weight gain during pregnancy, kg & $12.6 \pm 3.5$ & $15.0 \pm 4.0$ & .2 \\
Height, cm & $\mathrm{I} 69 \pm 6$ & $\mathrm{I} 70 \pm 7$ & .3 \\
BMl first trimester, kg/m ${ }^{2}$ & $25.7 \pm 3.7$ & $26.4 \pm 4.4$ & .6 \\
Gestational age, years & $28 \mathrm{I} \pm 4$ & $284 \pm 9$ & .2 \\
Birth weight, g & $3543 \pm 263$ & $4650 \pm 484$ & $.00 \mathrm{I}$ \\
Birth weight, SDS & $0.05 \pm 0.5 \mathrm{I}$ & $2.3 \mathrm{I} \pm 0.72$ & $.00 \mathrm{I}$ \\
\hline
\end{tabular}

Abbreviations: BMI, body mass index; LGA, large for gestational age; SD, standard deviation score.

${ }^{\mathrm{a}}$ Data presented as mean $\pm \mathrm{SD}$ or median (range).

Three of the women who gave birth to LGA infants were treated for hypothyroidism, but they all had normal serum levels of thyroid-stimulating hormone during their pregnancy. Ten women were delivered by cesarean section ( 6 cases and 4 controls); only 4 of these were planned and the remaining 6 were emergency cesarean sections. In the control group, 13 of the infants were girls and in the LGA group 12 of the infants were girls. Two of the LGA infants were admitted to neonatal care. One of the control infants had Apgar score 6 at 5 minutes, and all of the other infants had Apgar score 8 or above at 5 minutes.

\section{Expression Profiling of Placenta Tissue From Women Giving Birth to LGA Infants and AGA Infants}

Although a liberal threshold was used, only 29 up- or downregulated genes with a fold change greater than 0.5 were identified, Table 2. Top upregulated molecules were genes coding for $I G F B P 1$, aminolevulinate $\delta$ synthase 2 , and $P R L$, while the top downregulated molecules were genes coding for leptin $(L E P)$, gametocyte-specific factor 1, and collagen, type XVII, $\alpha 1$ (COL17A1). Some of the genes previously associated with increased fetal weight were also differently expressed in the micro array although with below threshold fold changes (peroxisome proliferator-activated receptor $\gamma$ fold change 0.16 , $P<.01$; IGF-I fold change $0.35, P<.01$ ).

We then visualized the differentially expressed genes using hierarchical clustering of genes in LGA versus AGA placentas (Figure 1).

In order to determine the biological relevance, IPA, focusing on genes that differed in expression between placentas from LGA pregnancies and AGA pregnancies, was performed. We identified 2 gene networks that were significantly enriched and classified as follows: (1) lipid metabolism, small molecule biochemistry, and organismal development with an IPA score of 21 and (2) cellular development, cellular growth, proliferation, and tumor morphology with an IPA score of 21 (Table 3). 
Table 2. Pathway Analysis of the Differentially Regulated Placental Genes in LGA Cases.

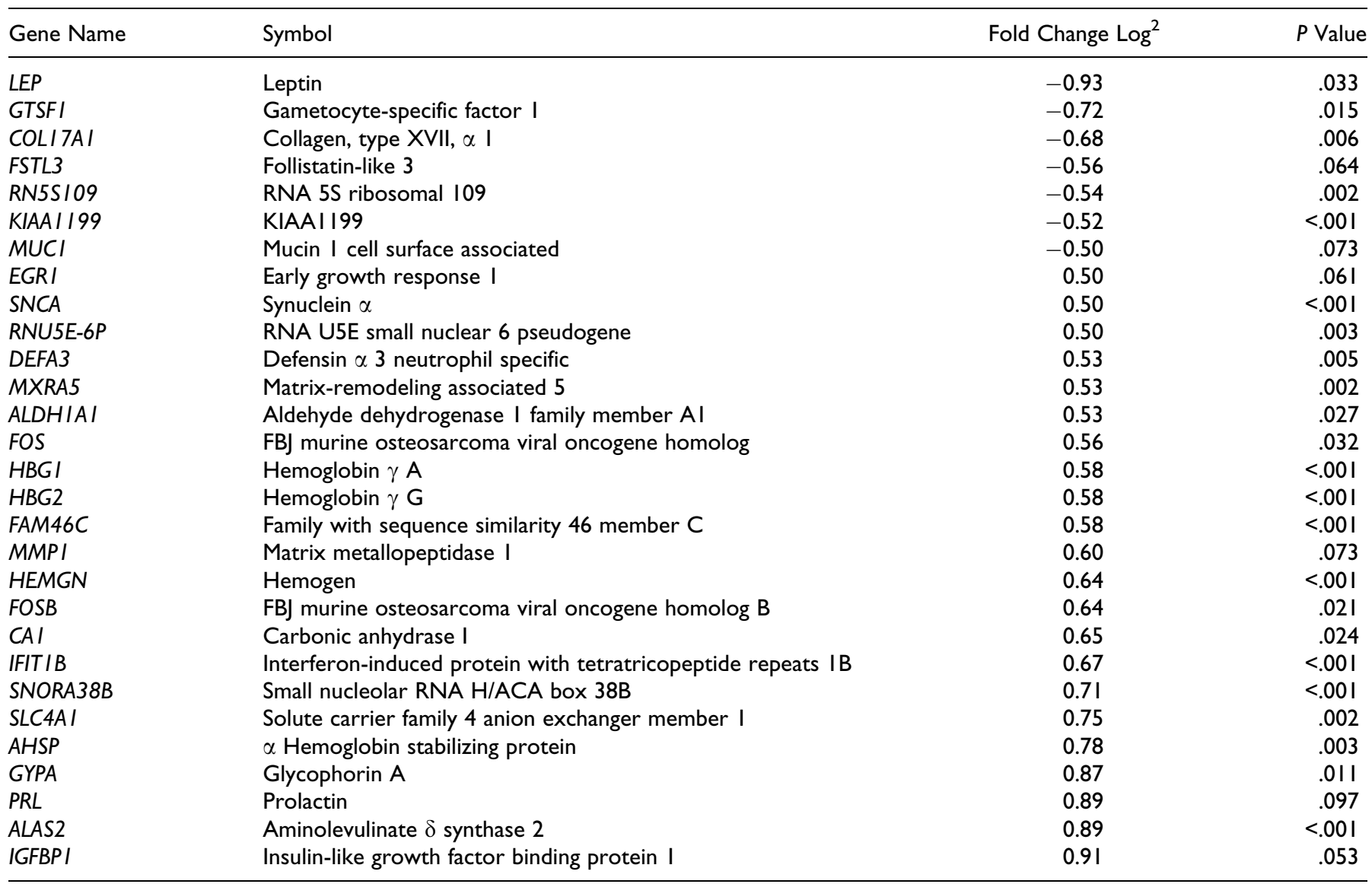

Abbreviation: LGA, large for gestational age.

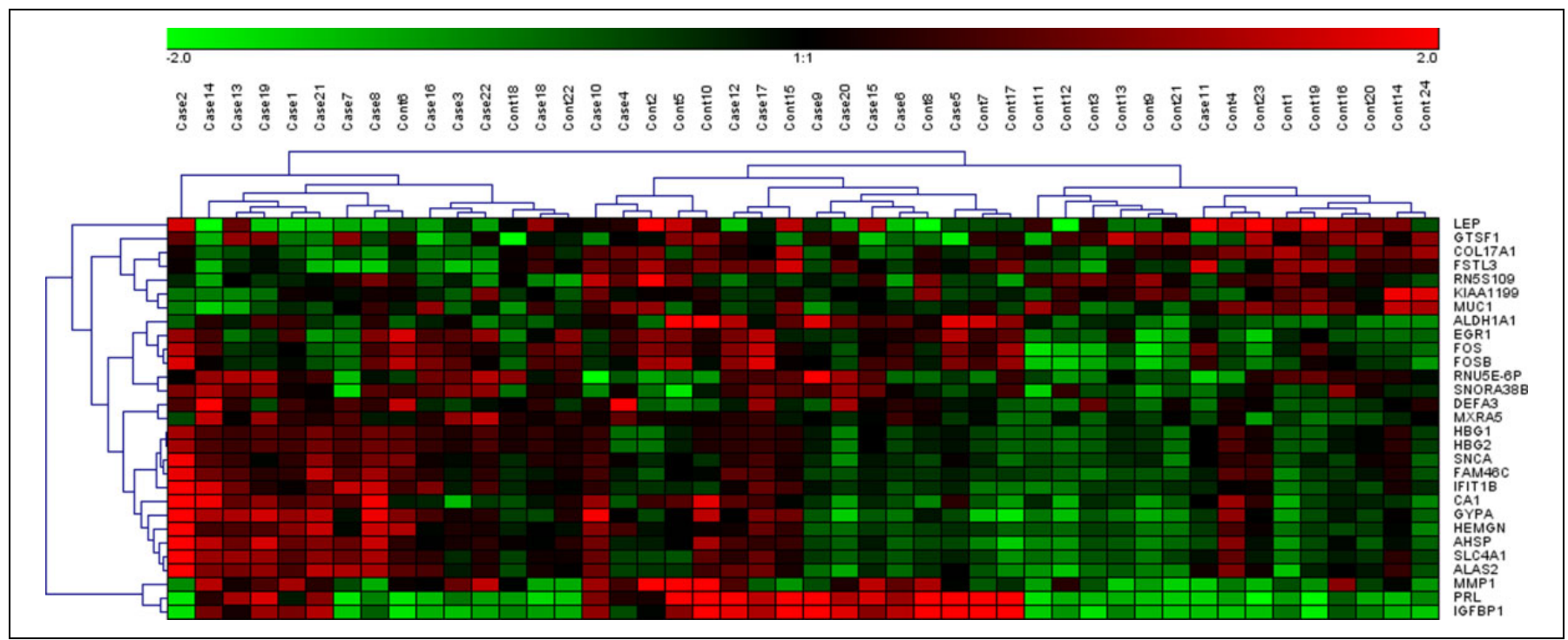

Figure I. Messenger RNA (mRNA) profiles of samples from large for gestational age placentas $(n=22)$ and appropriate for gestational age placentas $(n=24$; average linkage, correlation similarity). Samples are in columns and mRNA in rows.

Further, the significant canonical pathways identified by IPA $(P<.01)$ are shown in Table 4, along with the included genes and $P$ values. These included interleukin 17A signaling in fibroblasts, retinoid acid receptor activation, pregnane $\mathrm{X}$ receptor/retinoid X receptor activation, prolactin signaling, and glucocorticoid receptor signaling. 
Table 3. Enriched Ingenuity Pathway Analysis (IPA) Categories Including Differentially Expressed Genes in LGA Cases.

\begin{tabular}{llr}
\hline & & \multicolumn{1}{c}{$P$} \\
IPA Network & Gene & Value \\
\hline Lipid metabolism, small molecule biochemistry, & AHSP & .003 \\
organismal development (IPA score 2I) & EGRI & .061 \\
& FOS & .032 \\
& FOSB & .021 \\
& IGFBPI & .053 \\
& LEP & .033 \\
& MMPI & .073 \\
& MUCI & .073 \\
Cellular development, cellular growth, & PRL & .097 \\
Proliferation, and tumor morphology & SNCA & $<.001$ \\
(IPA score 2I) & ALAS2 & $<.001$ \\
& ALDHIAI & .027 \\
& COLI 7AI & .006 \\
& FSTL3 & .064 \\
& GYPA & .011 \\
& IGFBPI & .053 \\
& KIAAII 99 & $<.001$ \\
& LEP & .033 \\
& MUCI & .073 \\
& SLC4AI & .002 \\
\hline
\end{tabular}

Abbreviations: ALAS2, aminolevulinate $\delta$ synthase 2; COLI7AI, collagen, type XVII, $\alpha$ I; IGFBPI, insulin-like growth factor binding protein I; LEP, leptin; LGA, large for gestational age.

Table 4. Canonical Pathway Analysis.

\begin{tabular}{lll}
\hline Canonical Pathway & Genes & $P$ Value IPA \\
\hline $\begin{array}{ll}\text { IL-I7A signaling in } \\
\text { fibroblasts }\end{array}$ & FOS, MMPI & $1.53 \mathrm{E}^{-03}$ \\
RAR activation & FOS, MMPI, ALDHIAI & $2.56 \mathrm{E}^{-03}$ \\
PXR/RXR activation & ALDHIAI, IBFBPI & $4.45 \mathrm{E}^{-03}$ \\
Prolactin signaling & PRL, FOS & $6.52 \mathrm{E}^{-03}$ \\
Glucocorticoid receptor & FOS, MMPI, PRL & $7.13 \mathrm{E}^{-03}$ \\
$\quad$ signaling & & \\
\hline
\end{tabular}

Abbreviations: IL-I7A, interleukin I7A; IPA, ingenuity pathway analysis; PXR, pregnane $X$ receptor; $R A R$, retinoid acid receptor; $R X R$, retinoid $X$ receptor.

\section{Confirmation of Array Data Using Real-Time Quantitative Polymerase Chain Reaction Analysis}

To confirm the array data, we selected 5 differentially expressed genes in functionally relevant pathways. LEP, coding for leptin, which plays a major role in the regulation of body weight, food intake, and adipose mass both in the pregnant and in the nonpregnant state. IGFBP-1, a member of the insulin-like growth factor binding proteins, which regulates the amount of free circulating IGF-1. FOSB involved in forming transcription factor complex AP-1; as such, the FOS proteins have been implicated as a regulator of cell proliferation, differentiation, and transformation. $P R L$, encoding for the anterior pituitary hormone prolactin, which is a growth regulator for many tissues, including cells of the immune system. Finally,

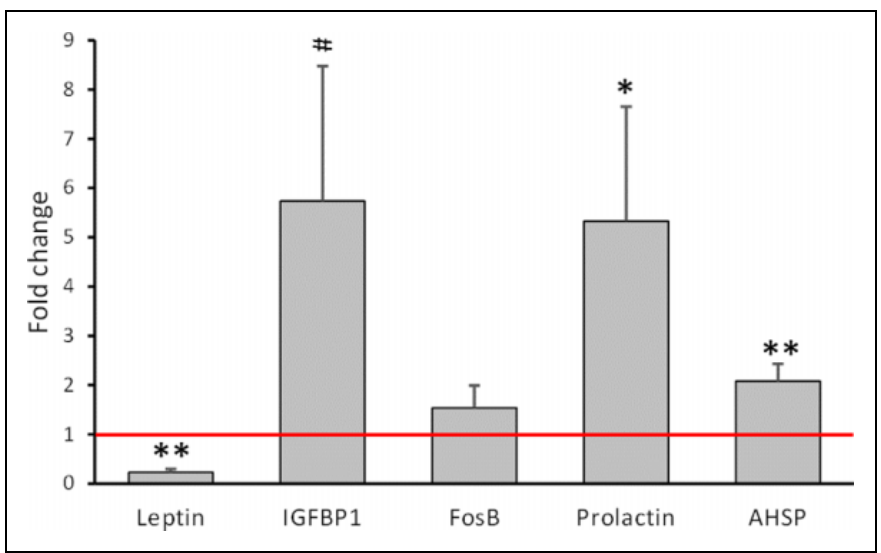

Figure 2. For validation of the microarray results, 5 genes, which showed a fold change $>0.6$ in the microarray, were selected. RQ$P C R$ validation of leptin (LEP), insulin-like growth factor binding protein I (IGFBPI), FOSB, prolactin (PRL), and $\alpha$-hemoglobin-stabilizing protein $(A H S P)$ genes in large for gestational age $(n=24)$ and appropriate for gestational age $(n=24)$ placentas. Gene expression values are presented as mean \pm standard deviation (SD). $* P<.05$, $* * P<.01$, and $\# P=.074$.

$A H S P$, coding for $\alpha$-hemoglobin-stabilizing protein, which provides protection against damaging oxidative reactions. The microarray analysis was partially confirmed, as placental expression of $L E P, \mathrm{t}(1,46)=-2.82, P<.01, P R L, \mathrm{t}(1,46)=$ $2.13, P<.05$, and $A H S P, \mathrm{t}(1,46)=2.71, P<.01$, was significantly different in the LGA group, whereas $I G F B P-1, \mathrm{t}(1,46)=$ $1.83, P=.074$, and $F O S B, \mathrm{t}(1,46)=0.961$, not significant, did not reach statistical significance in the RT-Q-PCR analysis (Figure 2).

\section{Discussion}

In this case-control study, we show with genome wide microarray technique that there are surprisingly few differences in global gene expression pattern between placentas from nondiabetic healthy women giving birth to LGA infants and placentas from BMI-matched women giving birth to AGA infants. Possibly, the relatively low number of differently expressed genes is due to the fact that we specifically focused on healthy women giving birth to LGA infants and that matching for other known risk factors such as BMI and weight gain was successful. Nevertheless, the findings we obtained indicate that genes involved in lipid metabolism pathways, including leptin and prolactin, seem to be differently expressed in placentas from women giving birth to LGA infants.

The leptin gene was downregulated in placentas from women giving birth to LGA infants. Leptin is of interest, given its involvement in satiety control, regulation of body fatness, insulin resistance, and energy expenditure. During pregnancy, serum concentrations of leptin increase by the action of pregnancy-specific hormones and as a consequence of central leptin resistance. ${ }^{22}$ However, the regulation of maternal leptin during pregnancy is complex, and production and regulation by 
adipose tissue as well as the placenta are thought to contribute to the pregnancy-induced increase. ${ }^{23}$ In relation to our results, it is well known that leptin levels in cord blood are related to infant size. ${ }^{24}$ Further, although the relationship between maternal leptin levels and fetal weight has been difficult to establish, ${ }^{25}$ a number of recent studies have suggested increased leptin to be a strong negative predictor for birth weight and LGA infant, even after adjustment for important covariates such as prepregnancy BMI and weight gain during pregnancy. ${ }^{26,27}$ Our finding is also in line with studies suggesting that placentas from mothers with gestational diabetes (unless treated with insulin ${ }^{28,29}$ ) releases less leptin compared to mothers with normal pregnancies, ${ }^{30}$ and findings from our group suggesting that also women with polycystic ovary syndrome have downregulated placental leptin and leptin receptor gene expression. ${ }^{31}$ Finally, our finding is also in agreement with studies on placentas from intrauterine growth restriction (IUGR) pregnancies where leptin gene expression was increased, although the mechanism in IUGR may be compensatory due to hypoxia and thus different from the placental milieu of the LGA infant. ${ }^{32}$

Further, we showed that the gene expression of prolactin was increased in the placentas from the LGA pregnancies. Prolactin is important for fetal growth and serum levels in the pregnant woman increases throughout gestation. ${ }^{33}$ Prolactin maintains and increases maternal food intake in the later stage of pregnancy by induction of central leptin resistance and promotes maternal (and fetal) beta-cell expansion and insulin production to defend against the development of gestational diabetes. ${ }^{34}$ For this reason, it is surprising that only 1 study has evaluated prolactin in LGA infants, suggesting an inverse correlation between maternal prolactin levels in gestational week 27 and birth weight. ${ }^{35}$ However, our findings are also in line with a prior study showing that the expression profile of placental growth hormone $(G H)$ /chorionic somatomammotropin hormone genes, which all interact with the GH/PRL/cytokine receptors, are altered in placentas from pregnancies accompanied by SGA and LGA. ${ }^{36}$ Clearly, our finding of increased $P R L$ expression in the LGA placentas suggest that prolactin plays a role, although it is unclear if it is primary or compensatory, and further studies in LGA infants are warranted.

In addition to leptin and prolactin, validation also secured a role for the AHSP in LGA. During hemoglobin synthesis, the AHSP specifically binds free alpha-hemoglobin subunits, thus limiting the production of the reactive oxygen species. While the role of $A H S P$ is unclear in LGA, previous studies have pointed to its relevance for placental function in that low expression levels have been associated with recurrent miscarriage ${ }^{37}$ severe preeclampsia and intrauterine fetal death. ${ }^{38}$

Expression of IGFBPI in LGA placenta was increased, although the difference did not reach statistical significance. Previous studies on placental IGFBP1 have suggested increased placental expression in intrauterine growth restriction. ${ }^{32,39}$ Again, the findings in LGA placenta may not be readily comparable with intrauterine growth restriction, the latter also being characterized by placental insufficiency and reduced availability of oxygen. ${ }^{40}$
In the IPA analysis, lipid metabolism came out as 1 important biological pathway in the placentas from women giving birth to LGA infants, exemplified for instance by EGRl, which controls lipolysis in adipocytes, ${ }^{41}$ and $M U C$ which directly regulates expression of a number of metabolic genes. ${ }^{42}$ Previous studies have suggested altered placental expression of genes involved in lipid metabolism in obese mothers and in mothers with insulin-dependent diabetes mellitus (IDDM) or gestational diabetes. ${ }^{43-45}$ For instance, Dube and colleagues reported an increase in placental lipoprotein lipase (LPL) activity and a decrease in solute carrier family 27 member 4 (SLC27A4) expression level in the placenta from obese women. ${ }^{46}$ However, these changes in placental gene expression were not associated with altered birth weight of the infants. Further, Magnusson et $\mathrm{al}^{47}$ reported an increased LPL activity in placentas of IDDM pregnancies by $39 \%$ which also corresponded to an increased birth weight of the infants in the IDDM group. Thus, our findings strengthen the hypothesis that lipid metabolism and transport is important not only for the fetal brain and eye development, the regulation of the fetal blood pressure, smooth muscle contraction, and blood clothing, but also that lipids may contribute as a source of energy to promote fetal growth. In addition, the similarities noted between our healthy patient population and previous studies in GDM underlines the fact that maternal hyperglycemia, although not fulfilling criteria for GDM, may be associated with increased risk of giving birth to an LGA infant. ${ }^{4}$

The cases included in this study were carefully chosen from a large bio bank, which made it possible to exclude those with possible confounders and investigate placentas from exposed and unexposed women with very similar characteristics. The randomly selected controls were matched on age, parity, first-trimester BMI, and gestational age at birth, and those cases and controls who had chronic diseases and/or daily medication were excluded. However, as the screening for GDM was based on clinical routine, and as the best screening strategy or glucose targets for GDM remains to be established ${ }^{48}$ it is however possible that undiagnosed cases with GDM may have been hidden among the cases. Additional limitations include the lack of blood samples from these women at the time of birth, why levels of leptin and prolactin at the time of birth could not be established.

\section{Conclusion}

The $L E P$ gene coding for leptin is downregulated and the $P R L$ gene coding for prolactin is upregulated in placentas from women giving birth to LGA infants. The downregulation of leptin is consistent with findings in patients with gestational diabetes and polycystic ovary syndrome and with findings suggesting maternal leptin serum concentrations to be a negative predictor of LGA. The upregulation of the $P R L$ gene is in line with the fact that prolactin is involved in appetite regulation via induction of central leptin resistance. Clearly, further studies on mechanisms leading to LGA are warranted in order to find 
appropriate interventions in the short- and long-term perspective for these children and their mothers.

\section{Acknowledgments}

The authors are grateful to Narges Zea for excellent technical assistance with the RNA extraction. We also thank Helena Kaihola and Hanna Göransson Kultima, Uppsala University, for skillful assistance.

\section{Authors' Note}

F. Ahlsson and H. Åkerud contributed equally to this work.

\section{Declaration of Conflicting Interests}

The author(s) declared no potential conflicts of interest with respect to the research, authorship, and/or publication of this article.

\section{Funding}

The author(s) disclosed receipt of the following financial support for the research, authorship, and/or publication of this article: This work was supported by the Gillberg Foundation, the Throne-Holst Foundation, HKH crown prince's Lovisas Foundation for children's healthcare, the Swedish Society for Medical Research, and the Swedish Medical Society.

\section{References}

1. Surkan PJ, Hsieh CC, Johansson AL, Dickman PW, Cnattingius $\mathrm{S}$. Reasons for increasing trends in large for gestational age births. Obstet Gynecol. 2004;104(4):720-726.

2. Ahlsson F, Gustafsson J, Tuvemo T, Lundgren M. Females born large for gestational age have a doubled risk of giving birth to large for gestational age infants. Acta Paediatr. 2007;96(3): 358-362.

3. Badon SE, Dyer AR, Josefson JL. Gestational weight gain and neonatal adiposity in the Hyperglycemia and Adverse Pregnancy Outcome study-North American region. Obesity (Silver Spring). 2014;22(7):1731-1738.

4. Catalano PM, McIntyre HD, Cruickshank JK, et al. The hyperglycemia and adverse pregnancy outcome study: associations of GDM and obesity with pregnancy outcomes. Diabetes Care. 2012;35(4):780-786.

5. Pedersen J. Weight and length at birth of infants of diabetic mothers. Acta Endocrinol (Copenh). 1954;16(4):330-342.

6. Ahlsson F, Diderholm B, Jonsson B, et al. Insulin resistance, a link between maternal overweight and fetal macrosomia in nondiabetic pregnancies. Horm Res Paediatr. 2010;74(4):267-274.

7. Kappen C, Kruger C, MacGowan J, et al. Maternal diet modulates placenta growth and gene expression in a mouse model of diabetic pregnancy. PLoS One. 2012;7(6):e38445.

8. Zhu MJ, Du M, Nathanielsz PW, Ford SP. Maternal obesity up-regulates inflammatory signaling pathways and enhances cytokine expression in the mid-gestation sheep placenta. Placenta. 2010;31(5):387-391.

9. Gheorghe CP, Goyal R, Holweger JD, Longo LD. Placental gene expression responses to maternal protein restriction in the mouse. Placenta. 2009;30:411-417.

10. Nishizawa H, Pryor-Koishi K, Kato T, Kowa H, Kurahashi H, Udagawa Y. Microarray analysis of differentially expressed fetal genes in placental tissue derived from early and late onset severe pre-eclampsia. Placenta. 2007;28(5-6):487-497.

11. Dunk CE, Roggensack AM, Cox B, et al. A distinct microvascular endothelial gene expression profile in severe IUGR placentas. Placenta. 2012;33(4):285-293.

12. Diaz M, Bassols J, Lopez-Bermejo A, Gómez-Roig MD, de Zegher F, Ibáñez L. Placental expression of peroxisome proliferator-activated receptor gamma (PPARgamma): relation to placental and fetal growth. J Clin Endocrinol Metab. 2012; 97(8):E1468-E1472.

13. Iniguez G, Gonzalez CA, Argandona F, Kakarieka E, Johnson MC, Cassorla F. Expression and protein content of IGF-I and IGF-I receptor in placentas from small, adequate and large for gestational age newborns. Horm Res Paediatr. 2010;73(5): 320-327.

14. Irizarry RA, Hobbs B, Collin F, et al. Exploration, normalization, and summaries of high density oligonucleotide array probe level data. Biostatistics. 2003;4(2):249-264.

15. Li C, Wong WH. Model-based analysis of oligonucleotide arrays: expression index computation and outlier detection. Proc Natl Acad Sci USA. 2001;98(1):31-36.

16. Smyth GK. Linear models and empirical bayes methods for assessing differential expression in microarray experiments. Stat Appl Genet Mol Biol. 2004;3:Article3.

17. Smyth GK. Limma: linear models for microarray data. In: Gentlemen R, Carey V, Dudoit S, Irizarry R, Huber W, eds. Bioinformatics and Computational Biology Solutions Using $R$ and Bioconductor. New York: Springer; 2005:397-420.

18. Benjamini Y, Hochberg Y. Controlling the false discovery rate: a practical and powerful approach to multiple testing. J Royal Stat Soc Series B. 1995;57(1):289-300.

19. Sturn A, Quackenbush J, Trajanoski Z. Genesis: cluster analysis of microarray data. Bioinformatics. 2002;18(1):207-208.

20. Vestergaard AL, Knudsen UB, Munk T, Rosbach H, Martensen PM. Transcriptional expression of type-I interferon response genes and stability of housekeeping genes in the human endometrium and endometriosis. Mol Hum Reprod. 2011;17(4):243-254.

21. Livak KJ, Schmittgen TD. Analysis of relative gene expression data using real-time quantitative PCR and the 2(-Delta Delta C(T)) method. Methods. 2001;25(4):402-408.

22. Grattan DR, Ladyman SR, Augustine RA. Hormonal induction of leptin resistance during pregnancy. Physiol Behav. 2007;91(4): 366-374.

23. Henson MC, Castracane VD. Leptin in pregnancy: an update. Biol Reprod. 2006;74(2):218-229.

24. Manderson JG, Patterson CC, Hadden DR, Traub AI, Leslie H, McCance DR. Leptin concentrations in maternal serum and cord blood in diabetic and nondiabetic pregnancy. Am J Obstet Gynecol. 2003;188(5):1326-1332.

25. Ahlsson F, Diderholm B, Ewald U, et al. Adipokines and their relation to maternal energy substrate production, insulin resistance and fetal size. Eur J Obstet Gynecol Reprod Biol. 2013; 168(1):26-29.

26. Verhaeghe J, van Bree R, Van Herck E. Maternal body size and birth weight: can insulin or adipokines do better? Metabolism. 2006;55(3):339-344. 
27. Retnakaran R, Ye C, Hanley AJ, et al. Effect of maternal weight, adipokines, glucose intolerance and lipids on infant birth weight among women without gestational diabetes mellitus. CMAJ. 2012;184(12):1353-1360.

28. Lepercq J, Cauzac M, Lahlou N, et al. Overexpression of placental leptin in diabetic pregnancy: a critical role for insulin. Diabetes. 1998;47(5):847-850.

29. Lea RG, Howe D, Hannah LT, Bonneau O, Hunter L, Hoggard N. Placental leptin in normal, diabetic and fetal growth-retarded pregnancies. Mol Hum Reprod. 2000;6(8):763-769.

30. Lappas M, Yee K, Permezel M, Rice GE. Release and regulation of leptin, resistin and adiponectin from human placenta, fetal membranes, and maternal adipose tissue and skeletal muscle from normal and gestational diabetes mellitus-complicated pregnancies. J Endocrinol. 2005;186(3):457-465.

31. Maliqueo M, Sundstrom Poromaa I, Vanky E, et al. Placental STAT3 signaling is activated in women with polycystic ovary syndrome. Hum Reprod. 2015;30(3):692-700.

32. Struwe E, Berzl G, Schild R, et al. Microarray analysis of placental tissue in intrauterine growth restriction. Clin Endocrinol (Oxf). 2010;72(2):241-247.

33. Newbern D, Freemark M. Placental hormones and the control of maternal metabolism and fetal growth. Curr Opin Endocrinol Diabetes Obes. 2011;18(6):409-416.

34. Nielsen JH, Galsgaard ED, Moldrup A, et al. Regulation of beta-cell mass by hormones and growth factors. Diabetes. 2001;50(suppl 1): S25-S29.

35. Lagiou P, Samoli E, Hsieh CC, et al. Maternal and cord blood hormones in relation to birth size. Eur J Epidemiol. 2014;29(5):343-351.

36. Mannik J, Vaas P, Rull K, Teesalu P, Rebane T, Laan M. Differential expression profile of growth hormone/chorionic somatomammotropin genes in placenta of small- and large-for-gestational-age newborns. J Clin Endocrinol Metab. 2010;95(5):2433-2442.

37. Emanuelli M, Cecati M, Sartini D, et al. Placental Alpha Hemoglobin Stabilizing Protein (AHSP) and recurrent miscarriage. Cell Stress Chaperones. 2009;14(2):193-197.

38. Emanuelli M, Sartini D, Rossi V, et al. Alpha-hemoglobinstabilizing protein (AHSP) in hemolysis, elevated liver enzyme, and low platelet (HELLP) syndrome, intrauterine growth restriction (IUGR) and fetal death. Cell Stress Chaperones. 2008;13(1): 67-71.

39. Okamoto A, Endo H, Kalionis B, et al. IGFBP1 and Follistatinlike 3 genes are significantly up-regulated in expression profiles of the IUGR placenta. Placenta. 2006;27(2-3):317-321.

40. Cetin I, Alvino G. Intrauterine growth restriction: implications for placental metabolism and transport. A review. Placenta. 2009; 30(suppl A):S77-S82.

41. Singh M, Kaur R, Lee MJ, et al. Fat-specific protein 27 inhibits lipolysis by facilitating the inhibitory effect of transcription factor Egr1 on transcription of adipose triglyceride lipase. J Biol Chem. 2014;289(21):14481-14487.

42. Mehla K, Singh PK. MUC1: a novel metabolic master regulator. Biochim Biophys Acta. 2014;1845(2):126-135.

43. Kleiblova P, Dostalova I, Bartlova M, et al. Expression of adipokines and estrogen receptors in adipose tissue and placenta of patients with gestational diabetes mellitus. Mol Cell Endocrinol. 2010;314(1):150-156.

44. Radaelli T, Lepercq J, Varastehpour A, Basu S, Catalano PM, Hauguel-De Mouzon S. Differential regulation of genes for fetoplacental lipid pathways in pregnancy with gestational and type 1 diabetes mellitus. Am J Obstet Gynecol. 2009;201:209. e1-e209. e10.

45. Enquobahrie DA, Williams MA, Qiu C, Meller M, Sorensen TK. Global placental gene expression in gestational diabetes mellitus. Am J Obstet Gynecol. 2009;200(2):206. e1-e13.

46. Dube E, Gravel A, Martin C, et al. Modulation of fatty acid transport and metabolism by maternal obesity in the human full-term placenta. Biol Reprod. 2012;87(1):14, 1-11.

47. Magnusson AL, Waterman IJ, Wennergren M, Jansson T, Powell TL. Triglyceride hydrolase activities and expression of fatty acid binding proteins in the human placenta in pregnancies complicated by intrauterine growth restriction and diabetes. J Clin Endocrinol Metab. 2004;89(9):4607-4614.

48. Prutsky GJ, Domecq JP, Sundaresh V, et al. Screening for gestational diabetes: a systematic review and meta-analysis. $J$ Clin Endocrinol Metab. 2013;98(11):4311-4318. 